\title{
Common Legal Regulations of Employees Rights to Vacations from Jordan Labour Law
}

\author{
Hasan Salih Suliman Al-Qudah \\ Department of Health Service and Hospital Management, College of Business - Rabigh Branch, King Abdul Aziz University, Rabigh, \\ Kingdum of Saudi Arabia
}

\section{Email address:}

hasancare@gmail.com, hasancare@yahoo.co

\section{To cite this article:}

Hasan Salih Suliman Al-Qudah. Common Legal Regulations of Employees Rights to Vacations from Jordan Labour Law. Science Journal of Business and Management. Vol. 3, No. 6, 2015, pp. 258-262. doi: 10.11648/j.sjbm.20150306.17

\begin{abstract}
Jordanian legislator at present took under consideration certain regulations to employee's right obtaining vacation. However, by revising some all of these provisions would lead us to note that some other provision did not have any consideration by other legislature, because it is related to wide range of legal common principles regarding to previous importance of vacations prospective. One of many provisions relating to vacations; is the principle independence of vacations, other issues regardless to vacations also the non-calculated vacations during holidays unless interrupted or prohibition of employee deprivation during vacation. The study will try to highlights some of above principles by discussing wide range of many tracking issues which are associated with them, the study would also conclude on the legal principles for vacations that shall be included in the provisions of Labour Law.
\end{abstract}

Keywords: Holidays, Vacation, Unfair Firing, Employee Rights

\section{Introduction}

Vacation prospective is considered to be as one and most important Jordanian laborers rights that took place under Jordanian legislator organized. Act.1996 of Labor Law No.(8). The reason behind that stand, the amount it touches interests of every employee, as it affects majority of livelihood at many different circumstances to all Jordanian work force. Special considerations were given to them in terms of stability as it gives an opportunity to obtain their high level of extensive good health and cultural education, yet Jordanian legislatures also impose these considerations in differences to vacation prospective, as it focus to the interests of employees to meet their different needs, so it was not surprising that legislature had granted workers their right as to have multiple and varied vacations permits in essence. These grants aspects includes holiday or vacations of "annual leaves, or sick leaves, or maternity vacations or pilgrimage or leaving abroad for higher education fellowship, also full-time leaves like raising of children or Spouse accompany to work outside

Legislatures have completed the review of some regulation provisions related to vacations, as they took into account achievements of some desire goals on behalf of approved regulation by making these provisions related thereto, such as peremptory rules which related to public order, its then become clear to all not leave on specified times, or for a shorter period of any prescribed period, unless agreement was offended by provisions cited in Jordanian legislator such as increasing the duration of leave, or to alleviate some terms of fall dues, as employee shall be deemed to agreement.

\section{Terms of Study}

Vacation means making Justification to leave for short time of period. It has stated in dictionary as: "Permissible or; allowed him to do so". Iben Manthore, (2000.)

In other term it has defined "the worker's right to absence from work in accordance with conditions specified by labor law”. Malkawi Adnan. (2008).

\section{Problem of Study}

Since the provision of vacations peremptory rules characterized did not allow contravention, of who committed or violates vocational legal aspects, both parties agreed on some benefit of override some provisions relates to (vacations). 
It can be seen clearly her some issues and solutions which applies to all vacations prospective derives the provisions or may live up to be considered on legal principles and acquire presence status and reliability, so we can see that it can be applied on various vacations methods, without making any changes in each or every case, perhaps most important of these principles as "principle of independent vacations" or "principle of segregation ban during vacations" lastly "principle of no calculation within holiday if were interrupted".

Although, these principles as their importance did not received any adequate modified regulation, therefore legislature did not concluded all them as uncertainty and ambiguity is still surrounding some aspects related to it, particularly as it has been declared by legislator in some occasionally regarding to vacations prospective, yet question may arises about possible extending range of some legal provision of other vacations, like to what extent is vocational leave appropriate and the amount of its incompatible with nature of untold verdict or undecided verdicts about vacations. Lastly it will brings to us clear picture about possible needs for immediate legislative intervention to regulate these aspects of vacation and their own special legal texts, whether these texts are sufficient to achieve goals associated with it or not?

\section{Discussion}

\subsection{Independence of Vacation Requirement}

Principle of independence vacation is one and most important principles to provisions of vacation, Abdul Wadod Yahyia (2005). There shall not be any confusion on this principle requirement specially between any vocational holidays, or another terms of one of them. The wisdom behind it is that it falls on best interest of contemplated from each vacation which was determined by legislator. Legislature who they grants holiday "vacation", aims to achieve at most in interests of one parties and benefits, it's also then when worker be granted vacation they don't deserve it will obviously leads to emptied provisions of Labor Law, from its substance, which may not be exclude with according to circumvention of its provisions.

In other words, legislator assumed specific conditions to met for entitlement at each leaves of any vacation recognized by employee, so if any necessary entitlement to one were available to workers accordance with some limits set by legislature, this means that it is prohibited to shift any vocational given to any employees or any further vacation "leaves", since it's not permissible to grants them for any purposes, like training program vacation or else, this also can be work for famel labors may not be granted sick leave rather than maternity leave.

On the same way there shall not be any deducted days of sick leave or maternity leave-for example, annual vacation days, but rather than there shall not prohibited from calculated days of sick leave within days annual leave if interrupted, worker gets sick during annual vacation, in such a case should not be counted sick leave days of annual leave.

It can be seen while apply at Jordanian Court of Cassation, as stated in one of its decisions stated:(there is no correlation between annual vacation and sick leave, each has its own rule there shall not be calculated of sick leave from annual vacation, Labor Law did allow any vindication between both actual vacation. Legal Encyclopedia outrigger. (2000).

The working group entitlement of vacation doesn't affect entitlement on other vacation if conditions were available, it is no longer true for example-that employer's failure to grant working women sick leave or leave to care for children if they have enjoyed maternity vacation, worker's right is no Last preclude of entitlement, and amount to enjoys legal right does not fit a pretext to withhold his last.

Perhaps it is useful to note here that extended leaves is not excluded when calculating total days in one year of what employers deserves on other holiday, as they are all counted for purposes of annual leave entitlement, there for pursuant of vacation can be notified during working like "sick leave. Abdul Wadod Yahya (2000). Pilgrimage vacation however or maternity vacation is all stands for serving on behalf business owner favors. Saudi Labour Law (2005).

Therefore, it does not accept employer's to calculate of workers annual leave after excluding days of any leave obtained by any Group during previous year, as previous governance may not fully apply to some unpaid holiday, it is still difficult worthily estimate actual days of annual working or sick leave, during workers rejoice of any official leaves or vacations like accompany spouse or leave to raise children for full-time or full-time trade union leave, latter those relatively vacations may be long and may not convenience to some special provisions applying in other vacations.

Not far from this principle and its requirements, question may raise about possibility of employees taking advantage of one of his vacations if not enough for another vacation enjoyed by all fulfill their allocated purposes, and to extent as if they needed a working a couple of days more after exhausting sick leave, or if they need of more working days to study after exhausting period prescribed for education enrollment leave, so is it permissible for workers in such cases to take advantage of other vacation he did not exhausted?

This study considers that workers freedom to take advantage of all their holiday they deserves during full year will leads to provisions output of employees vacation rights, in other world any vacation is not awarded only to some circumstances and under certain conditions shall be according to legislature limitation, while to allow workers make used or exhausted breach and not to waste of those vacations in wise manners, without harming the interest of employer.

Looking in to other side, the study finds that employees interest must also not be overlooked, exhaustion factor for granted vocational limited period permit employer to be considered absent from work and allows him to stop calculating remuneration for that period, which upset 
undoubtedly in interests of employers.

Therefore we believe that it is good to adopt an intermediate position, by allowing worker in such cases to take advantage of an reserve of his annual legally vocational number of days as to unrealized and worthy of leave especially while adopting of such a solution it allows taking into account interests of both parties, that may not effected employer if may suffered of his granted, because workers cannot perform work permanently on desired at least face, as it will get his annual leave at a later time, so it would be good for employer to calculated those days from his annual leave, at a time when taking into account working's interests as well, without affecting him in his livelihood .

Based on above, we believe that Jordanian delegated shall improve text on this important principle explicitly in Labor law, so the study proposes to adapt following facts:

A. Worker shall not be granted any vacation other than that he deserves, but shall not affect employees to any entitlement vacation if he deserves that vacation.

B. There shall not be any exclusion in any period of year for any purposes as its employee's vocational rights, except to full-time raising children and Wife accompany or full-time trade union participation.

C. Utilization factor of employees annual vacations balance in some cases may not enough to him to any leave granted for any argent fulfillment of his presence.

\subsection{Prohibition Requirement of Segregate During Holiday}

In this second demand; Workers shall not be segregate during enjoyment of their leaves, which can be expressed as principle of segregate ban during holiday (there shall be no segregate during vacation), it can be inferred from text of Article (27 / A) in Jordanian Labor Law, as follow: (No employer may terminate of worker service or to send any notice to him to end his service in any of following cases:

A. Pregnant working women, starting from her sixth month of pregnancy or during maternity leave.

B. Working group on military service or in reserve duty while still in service.

C. Any worker who enjoys vacation, during annual leave or sick leave or given to him for any further labor education or who moves for pilgrimage or any vacation, which agreed between two parties to work for full-time trade union or to join any higher educational in colleges or a university.

The wisdom of this law, is to emanated from it, as it aims not to spoil worker enjoyment during vacation, since law guaranteed and allows to disconnect in meantime it means emptying his leave of its content no to be disrupt them, rather than not to mention that any rhythm of Chapter during leave can raises doubt about reasons behind it and amount of actual legal procedures related to it, as there is unlikely to be motivated by an attempt to get rid of employer obligations in face of world, especially to groups who are not on work.

As noted in previous encompassing text most holiday provided in legislator, considers as there shall not be dismissed during maternity leave, annual and sick leave and vacation Labor Culture and Hajj (pilgrims vacation), probably raises question about possibility of applying same principle in process of other holiday, question may arise about possible of workers segregation during vacation?

Its notes her that there shall not be differentiation or separation exclusively regarding to deferent vacations, as we can say about possibility of separation vacations obtained by the worker whether it was vacation stipulated legislator did not refer by previous version, in other word that full-time vacation for raising children or other vacation escort worker with wife, or any other vocational conventional, which were not exposed by legislator like leave to matrimony vacation. However, these elements may affect worker rights or interests, same time may raises question about the reason for excluding these licenses from law on previous article, the reason of differentiation between them as it referred to in Article (27/ A), workers in both cases has would enjoy his legal vocational statues in both cases as guaranteed by a legislator! It's not the words that explained how adoption of this provision shall be available in all vacation aspects!

Accordingly, its believe that the importance to reconsider some previous articles, as former Jordanian delegated pointed out to make in general way to cover all holiday.

However, embracing of former principle does not mean exit ban it in some cases, it has felt that Jordanian legislator allowed to cross over in some consideration like for worker to work during their leaves, as Article (27 / B) of Jordanian labor law as indicates that, Business owner in a unfastening of this provisions in paragraph (a) of this Article, if Laborer was posted in other work during any periods set forth in that paragraph.

So prohibition of laborer to obtain separate vacation during period of holiday remains subject factor to enjoy benefit, so that there are benefits of plausible achieved approval from all holiday, if it turns out that employer work during one vacation, it is to owners right to dismisses him of work.

The explanations of previous article is perhaps due to interpretation of laborer who works for another employer as a termination of relationship with first business owner, this was adopted in Court of Cassation at one of its decisions, as mentioned:(If worker got his annual vacation from his business owner which has been associated with to employment contract or with owner of other worker is considered this behavior detached from work with first business owner on his own. In this case it shall not be right to receive pay cut for duration of leave and need to be return salary he received as he does not entail right of remuneration as notice instead from first business owner who doesn't finished his services in first glance .

However, former explanation does not agree to extent indeed in many cases, The former verdict applies in cases of laborers metaphor if work for another business owner, it does not involve on some cases worker metaphor as they works on his own work, tacking inconsideration fact that in both cases laborer may have missed purpose of receiving a license, was inferred from his actions termination of employment from his first business owner relationship, so why to allow dismissal in first case, with no need for 
dismissing him in second case!

On other hand, what worker pays for work may be linked to his poverty and destitution and his desire to get some payments during leave, not in his desire to end relationship with his first work, but some believes that in depriving labors to work during their leave is unreasonably restricting to his freedom . Which leads to say that the previous procedure worker's right metaphor is not without its severity, at first its delegated believe his sufficient to deprive worker of his wages for the period during which he works during holiday, as it's so similar to what he did by the lawmakers like what came with legislator Egyptian and suggest for this purpose to adopt following concept:

The Business Honors may rhythm disciplinary penalty on worker and deprived of his wages for period of leave in each case proves work during which worker.

Finally it should be noted that there is a principle relevant to principle to ban that Chapter because of using employers factor of their rights to leave ( but not separately vacation or leave), as above mentioned it should not be clear understood of worker used on his right to leave and guaranteed a legislative matter to drag dilemmas form it.

\subsection{Calculating of Vacations Far from Previous or Subsequent Holidays}

The issue of how to calculate duration of any vacation, if it overlapped with one of any official holiday or public holiday is considered as key issues that might hinder employee and business owner in general as their interests shall run counter to or may opposed .It will be in interests of laborer deducted not to included any public holiday within days of leaving even if or while he is on his work, on contrary of that some requirement to interest of business owner allows them to calculates these days of absence within days of leave so to reduce number of days in which worker was cut off from work, and because intersection of those days of leave don't counted due to any reason related to Employer .

Therefore legislator directly took over sentencing statement in this process for annual holidays, as stated in Jordanian labor law article (61 / A) as following: (public holiday and religious holiday and weekly day of annual leave holiday and shall not be counted unless if signed through).

The advantaged official of this law for weekends or for any religious holiday shall conclude and shall be calculated if that holiday occurred at the first day of any commencement of such holiday that came prior or before last day, but if any holiday started before initiating or after its completion, then it shall not be counted at any holiday, this can be expressed according to" Calculating of vacation apart from past or subsequent holidays it". Even though previous version particularly relating to annual holidays, shall not managed to keep preclude dissemination of judgment on any previous holidays.

The previous version also meant to differentiate between the two cases, are as follows:

\subsubsection{The Case of Convergence Vacation Leave}

It can noticed her that convergence status of official or weekly or any religious holiday comes before leave began or following its expiry date (6), Abdel Baqi Abdel Fattah, (1993). as if "Eid al-Fitr "if this holiday comes before beginning of any annual or any sick leave or after their completion, in such situation it must not be accounted for vacation or holiday period within days of Leave , they must be joined to each other even with no diminution of worker's right to enjoy holidays".

\subsubsection{State of Overlapping Vacation with Official Holiday}

In this case when holiday comes during employers vacation, or when he takes an annual or sick leave for a period of time like for 10 days. In such case it must be included at least one of former vacation day off, according to previous law, laborers can't claim to include any day of his vacation, it must be counted for the employer number of legal or official vocation days he can have them during certain time of period, so its shall be clear that this justify by consternating on "giving to laborer a rest to get rid of work trouble", if worker is on annual leave its then it shall be considered to him and it shall not be replaced with any holidays . (6) Abdel Baqi Abdel Fattah, (1993).

According to the previous law it can be clear according to Article (61 / A) - is not limitation shall be given on weekly end day, but shall be extends to public holiday or religious festivals, which is hard to accept it or to justify it, on what basis employers may deprive form allocated to appropriate holiday extends for five days sometimes like" Al-Fitr feast or Eid Al-Adha", or other official national holidays, or what is the wisdom of calculating holiday or any other holiday within days of leave, which shall harm worker interests or to detract him from his right! This will obviously leads to open door in front of other business owners to get rid of allowing or permitting worker's of their annual leave or any maternity vacation by giving employers their vacation coincide with or during any other official holiday.

\section{Conclusion}

After viewing legal principles relating to workers' vacations study will recall most important findings and recommendations of study as following:

Results:

1. For each vacation determined by the legislator extremely could be achieved, and may not be circumventing by granting other vacation instead.

2. In same method, the actual cause for granting vacation to achieve the maximum benefits of worker interest and also to be self aware not release employers during vacation, Unless employers proven prejudice of their duties and responsibility .

3. Legislature expressly provided that they shall not count any holiday or any other official or weekly holiday part of any annual holiday unless it was intervened between them. 


\section{Recommendations}

The study finds some certain legal issues and suggestion of some provisions that can be adopted or can be modifayed by Jordanian labor law, these intended presumption and formulation speculation of legal provisions allocated for each principles presented by the study as following:

\section{Article I:}

A. Worker shall not be granted any other holiday other than that due to him, this shall not affect his rights to enjoy his entitlement holiday.

B. There shall not be any exclusion of any period of year to worker rights of holidays, exception of full-time vacation like rising of children or any vacation escort with worker wife whom she can travel to work outside country

C. Employees have right to utilize factor of the annual vacations balance in cases it was not enough of any vacation that was granted to him.

\section{Article II:}

This article may require to adopte by deleting Article (27) of Jordanian labor law like follows:

(Employer or Business owners may rhythm disciplinary action on worker to deprive them of their wage for the period of any leave in each case it proves that he works during his vacation.

\section{Article III:}

It is worth singling out a specific provision without prejudice to text of Article (61 / A) of Jordanian labor law.

(It is not permissible to calculate designate of any weekly holiday within period of any vacation unless it was signed through).

\section{References}

[1] Manzore Iben, lessan Alarab, Scholarship of Knowledge House, Alexandria, without year of publication.

[2] Abu Shanab Ahmed, Explain of new labor law, first-edition version IV, Cultural House, Amman- Jordan. 2009.

[3] Ramadan Mahmud, The mediator to explain labor law, first edition, House of Culture, Amman -Jordan. 2005.

[4] Malkawi Bashar Adnan, A glossary definitions of terms of private law, first edition, Dar Wael, Amman- Jordan. 2008.

[5] Abdel Baqi Abdel Fattah, The provisions relationship between worker and employer in Kuwaiti labor law. Kuwait. 1993.

[6] Karam Abdul Wahid, working in Jordanian Legislation Law, first edition, Culture House, Amman- Jordan. 1998.

[7] Yahya Abdul Wadud, Explain of labor law, Third Edition, Arab Renaissance Publishing House, Cairo, 1989.

[8] Daoudi Galb, Labor law Explaination, Third Edition, Dar Wael, Amman- Jordan. 2004.

[9] Murad Mohammed Helmi, Labor and Social Security Law, Fourth Edition, renaissance Egypt, Cairo Press. 1961.

[10] Legislation and judicial decisions.

[11] Jordanian Labor Law No. (8), 1996.

[12] Egyptian Labor Law No. (12), 2003.

[13] Saudi Labor Law, 2005.

[14] Discrimination Rights (244/1967), Law Association Journal, Amman - Jordan, 1967.

[15] Discrimination Rights (522/2000), Encyclopedia outrigger legal. Jordan mohamoon.com/medad. 